\title{
Polymalic acid nanobioconjugate for simultaneous inhibition of tumor growth and immunostimulation in HER2/neu-positive breast cancer $\lesssim$
}

\author{
Hui Ding ${ }^{\mathrm{a}, 1}$, Gustavo Helguera ${ }^{\mathrm{b}, 1,2}$, José A. Rodríguez ${ }^{\mathrm{b}, \mathrm{c}}$, Janet Markman ${ }^{\mathrm{a}}$, Rosendo Luria- \\ Pérez $^{b, 3}$, Pallavi Gangalum ${ }^{a}$, Jose Portilla-Arias ${ }^{a}$, Satoshi Inoue ${ }^{a, 4}$, Tracy R. Daniels-Wells ${ }^{b}$,

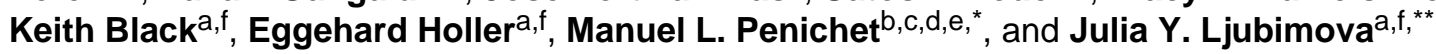 \\ aDepartment of Neurosurgery, Cedars-Sinai Medical Center, Los Angeles, USA \\ bDivision of Surgical Oncology, Department of Surgery, David Geffen School of Medicine, \\ University of California, Los Angeles, USA \\ 'The Molecular Biology Institute, University of California, Los Angeles, USA \\ dDepartment of Microbiology, Immunology, and Molecular Genetics, David Geffen School of \\ Medicine, University of California, Los Angeles, USA \\ eJonsson Comprehensive Cancer Center, University of California, Los Angeles, USA \\ fSamuel Oschin Comprehensive Cancer Center, Cedars-Sinai Medical Center, Los Angeles, USA
}

\section{Abstract}

Breast cancer remains the second leading cause of cancer death among women in the United States. The breast cancer prognosis is particularly poor in case of tumors overexpressing the oncoprotein HER2/neu. A new nanobioconjugate of the Polycefin family of anti-cancer drugs based on biodegradable and non-toxic polymalic acid (PMLA) was engineered for a multipronged attack on HER2/neu-positive breast cancer cells. An antibody cytokine fusion protein consisting of the immunostimulatory cytokine interleukin-2 (IL-2) genetically fused to an antibody specific for human HER2/neu [anti-HER2/neu IgG3-(IL-2)] was covalently attached to the PMLA backbone to target HER2/neu expressing tumors and ensuring the delivery of IL-2 to the tumor microenvironment. Antisense oligonucleotides (AON) were conjugated to the nanodrug to inhibit the expression of vascular tumor protein laminin-411 in order to block tumor angiogenesis. It is shown that the nanobioconjugate was capable of specifically binding human HER2/neu and retaining the biological activity of IL-2. We also showed the uptake of the nanobioconjugate by HER2/neu-positive breast cancer cells and enhanced tumor targeting in vivo. In addition, the nanobioconjugate was capable of eliciting anti-tumor activity in immunocompetent mice bearing

\footnotetext{
This is an open-access article distributed under the terms of the Creative Commons Attribution-Noncommercial-No Derivative Works License, which permits non-commercial use, distribution, and reproduction in any medium, provided the original author and source are credited.

(C) 2013 The Authors. Published by Elsevier B.V. All rights reserved

*Correspondence to: M.L. Penichet, Division of Surgical Oncology, Department of Surgery, University of California at Los Angeles (UCLA), 10833 Le Conte Avenue, CHS 54-140, Box 951782, Los Angeles, 90095-1782, USA. Tel.: +1 310825 1304; fax: +1 310 825 7575. penichet@mednet.ucla.edu (M.L. Penichet). Correspondence to: J.Y. Ljubimova, Department of Neurosurgery, CedarsSinai Medical Center, 8631 West Third Street, Suite 800E, Los Angeles, 90048, USA. Tel.: +1 310423 0834; fax: +1 3104230810 ljubimovaj@cshs.org (J.Y. Ljubimova)..

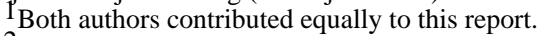

${ }^{2}$ Present address: School of Pharmacy and Biochemistry, University of Buenos Aires, Buenos Aires, Argentina.

${ }^{3}$ Present address: Unit of Investigative Research on Oncological Disease, Children's Hospital of Mexico "Federico Gomez", Mexico City, Mexico.

${ }^{4}$ Present address: Department of Trauma Surgery, School of Medicine, Saga University, Japan.
} 
D2F2/E2 murine mammary tumors that express human HER2/neu. Both IgG1 and IgG2a levels were significantly increased in animals treated with the PMLA-fusion nanobioconjugate compared to animals treated with the antibody-cytokine fusion protein alone or control animals, indicative of the induction of a humoral $\left(\mathrm{T}_{\mathrm{H}} 2\right)$ and cell-mediated $\left(\mathrm{T}_{\mathrm{H}} 1\right)$ immune responses. Animal survival in vivo was significantly longer after treatment with leading nanobioconjugate with fusion [antiHER2/neu IgG3-(IL-2)] antibody, $p<0.05$. The combination of these molecules on a single polymeric platform is expected to act through direct elimination of cancer cells, inhibition of tumor angiogenesis, and orchestration of a potent immune response against tumor.

\section{Keywords}

Polymalic acid; Nanobioconjugate; Nanopolymer; HER2/neu; Antibody fusion protein; IL-2; Laminin-411; Breast cancer

\section{Introduction}

According to the American Cancer Society, in 2013 an estimated 232,340 new cases of invasive breast cancer will be diagnosed among women and approximately 39,620 women are expected to die from breast cancer [1]. Although only 25-30\% of human breast and ovarian tumors overexpress the HER2/neu (epidermal growth factor receptor 2) protooncogene, the elevated level of HER2/neu in malignancies correlates strongly with poor prognosis [2-5]. Its extracellular accessibility makes it an excellent target for tumor-specific therapeutic agents. In fact, using the FDA-approved anti-HER2/neu antibody trastuzumab (Herceptin ${ }^{\circledR}$ ) alone or combined with chemotherapy in patients with advanced breast cancer leads to an objective response against tumors overexpressing HER2/neu [6-11]. However, a significant number of these patients do not respond to trastuzumab-based treatments and most that do initially respond acquire resistance within one year and eventually succumb to the disease [12-15]. Therefore, strategies for improved treatment of HER2/neu expressing cancers are still needed.

Interleukin-2 (IL-2) is a potent immunostimulator of both cellular and humoral adaptive immune responses and has been studied extensively as a potential cancer treatment $[16,17]$. It primarily not only stimulates T-cells to proliferate and become cytotoxic, but also activates a variety of immune cells including NK cells, lymphokine-activated killer (LAK) cells, monocytes, and macrophages [16]. Given the rapid blood clearance of IL-2 and its lack of tumor specificity, its therapeutic potential is limited since systemic administration of IL-2 in high doses is associated with severe toxicities, including vascular leak syndrome [17-19]. Therefore, our goal was to target sufficient quantities of IL-2 to the site of HER2/ $n e u$-expressing tumors using an antibody-cytokine fusion protein [20,21]. We previously developed an antibody-cytokine fusion protein that consists of human IL-2 genetically fused to the C-terminus of each heavy chain of an anti-HER2/neu IgG3 [anti-HER2/neu IgG3(IL-2)] [22]. We used human IL-2 since it is fully active in mice and human IgG3 due to its extended hinge region that confers spacing and flexibility [23]. Compared to other IgG isotypes (IgG1, IgG2, and $\operatorname{IgG} 4) \operatorname{IgG} 3$ is the most flexible [23]. We consider the extended hinge of human IgG3 of particular relevance in the context of its biorecognition and biological activity, since it would minimize steric hindrance and further facilitate binding to the antigen and cytokine receptor. This molecule was developed to enhance the tumoricidal activity of the antibody alone as well as elicit tumor specific immune responses due to the delivery of IL-2 to the tumor microenvironment. The extracellular domain of HER2/neu $\left(E C D^{\mathrm{HER} 2}\right)$ is insufficiently processed by dendritic cells and thus is poorly immunogenic [24]. Using immunostimulators such as IL-2 is expected to enhance the immunogenicity of HER2/neu. In fact, we have shown that the antibody-cytokine fusion protein is very 
efficiently internalized by dendritic cells and trafficked to antigen-processing compartments [25]. Importantly, the anti-HER2/neu IgG3-(IL-2) acts as a direct anti-cancer agent [22,26] as well as an adjuvant of ECD ${ }^{\mathrm{HER} 2}$ vaccination [25,27-29] in murine models under conditions where the antibody alone fails to confer protection. In all of our previous studies the anti-HER2/neu IgG3-(IL-2) was well-tolerated and no unexpected side-effects were observed in treated animals.

Combination therapy is a common practice for the treatment of breast cancer [30,31] and it may greatly improve patient survival using a strategy designed to combine immunotherapy with nanoparticles specifically targeting the tumor microenvironment [32]. Laminin-411 (formerly, laminin-8) and its integrin receptors $\alpha 6 \beta 1$ and a $5 \beta 1$ are important for the functioning of endothelial cell basement membranes [33,34]. It promotes cell migration during development, wound healing, and angiogenesis in vivo and in vitro [34-36]. We identified laminin-411 as a critical angiogenic marker of the brain and breast cancer [3740]. Using poly( $\beta$-L-malic acid) (PMLA)-based nanobioconjugates for targeted delivery of antisense oligonucleotides (AON) blocking the synthesis of laminin-411 chains indeed inhibited tumor cell migration and invasion [39,41].

PMLA, a natural product of the slime mold Physarum polycephalum [42-44], is a promising drug carrier well developed by our group. The attractive properties of PMLA as a carrier matrix for biopharmaceuticals are its lack of toxicity in vitro and in vivo, nonimmunogenicity, biodegradability, and versatility for drug loading. In this study, a PMLA nanobioconjugate was rationally designed for combination therapy to simultaneously deliver anti-HER2/neu IgG3-(IL-2) and AON against laminin-411 chains specifically to the tumor site in order to achieve increased therapeutic efficacy and reduce adverse effects to normal tissues. The nanobioconjugate based on PMLA as a drug carrier contains $40 \%$ leucine ethyl ester as an endosomal escape unit, anti-HER2/nеи IgG3-(IL-2) for tumor targeting and antitumor immunotherapy, and Morpholino AON against laminin-411 a4 and $\beta 1$ chains to inhibit tumor angiogenesis. The designed nanobioconjugate aims to reduce the toxicities of the cytokine, to improve the circulation time of the nanobioconjugate, and to inhibit breast cancer growth more efficaciously than anti-HER2/neu IgG3-(IL-2) alone.

\section{Materials and methods}

\subsection{Materials}

Highly purified, endotoxin-free PMLA, with a weight-averaged molecular weight (mw) of $60 \mathrm{kDa}$ and a polydispersity of 1.1, was obtained from the culture broth of $P$. polycephalum and size-fractionated on Sephadex G25 (GE Healthcare, Pittsburgh, PA). Cysteamine (2mercaptoethylamine hydrochloride), N-hydroxysuccinimide, and other reagents and solvents were purchased from Sigma-Aldrich (St. Louis, MO). Morpholino-3'-NH $\mathrm{NH}_{2}$ AON AGC-TCAAAG-CCA-TTT-CTC-CGC-TGA-C to laminin a 4 and CTA-GCA-ACT-GGA-GAAGCCCCA-TGC-C to laminin $\beta 1$ chains were custom made by Gene Tools (Philomath, OR). $\mathrm{mPEG}_{5000}$-amine and maleimide- $\mathrm{PEG}_{3400}$-maleimide were obtained from Laysan Bio, Inc. (Arab, AL). Alexa Fluor $680 \mathrm{C}_{2}$ maleimide and Alexa Fluor $488 \mathrm{C}_{5}$ maleimide were from Invitrogen (Carlsbad, CA).

\subsection{Cell lines and culture conditions}

Two human HER2/neu-positive breast cancer cell lines SK-BR-3 and BT-474 were obtained from American Type Culture Collection (Manassas, VA). BT-474 was cultured in DMEM with 10\% fetal bovine serum (FBS; Atlanta Biologicals, Lawrenceville, GA) and antibiotics. SK-BR-3 was cultured in RPMI-1640 medium with $10 \%$ FBS and antibiotics. The D2F2 mouse mammary tumor cell line (syngeneic to BALB/c mice) and that transfected with a 
vector encoding human HER2/neu (D2F2/E2) were kind gifts from Dr. Wei-Zen Wei (Wayne State University, Detroit, MI) [45] and were cultured in IMDM (Invitrogen) containing 10\% FBS. Growth media for D2F2/E2 was further supplemented with $1 \mathrm{mg} / \mathrm{ml}$ G418 (a selective antibiotic for the neomycin resistance gene) to maintain high expression of human HER2/neu.

\subsection{Production of the antibody-cytokine fusion protein, anti-HER2/neu IgG3-(IL-2)}

To improve the efficacy of the humanized antibody trastuzumab, we have genetically fused the IL-2 cytokine to a human IgG3 with the variable regions of trastuzumab (Herceptin ${ }^{\circledR}$ ). The scheme of genes encoding the heavy chain of the antibody-cytokine fusion protein is depicted in Fig. 1A and a schematic representation of fusion anti-HER2/neu IgG3-(IL-2) is depicted in Fig. 1B. Murine myeloma cells (P3X63-Ag8.653) expressing and secreting the antibody-cytokine fusion protein were grown in roller bottles and purified from cell culture supernatants using affinity chromatography as previously described $[22,46]$. Protein concentration was determined by bicinchoninic acid-based protein assay (BCA Protein Assay, Thermo Fisher Scientific Inc., Walnut Creek, CA). Purity and integrity were assessed by Coomassie blue staining of proteins separated by SDS-PAGE. The parental antibody without IL-2, anti-HER2/neu IgG3, has been previously described and used as a control in studies with the fusion protein [22,25-29]. In figures anti-HER2/neu IgG3 and anti-HER2/ nеи IgG3-(IL-2) are abbreviated [IgG3 and IgG3-(IL-2)] due to space constraints.

\subsection{Synthesis of PMLA-fusion nanobioconjugate, $P / m P E G / L O E t / l g G 3-(I L-2) / A O N(\alpha 4 \beta 1)$}

The copolymer PMLA/mPEG/LOEt/MEA containing 5\% mPEG, 40\% leucine ethyl ester (LOEt), and 10\% 2-mercaptoethylamine (MEA) was prepared as previously described (\% referring to the total amount of pendant carboxyl groups in PMLA) [41,47], where mPEG increases the stability of nanobioconjugate in bloodstream, LOEt serves as an endosomal escape unit to achieve cytoplasmic delivery, and MEA provides sufficient sulfhydryl groups for antibody conjugation, AON loading, and fluorescence labeling. The copolymer was conjugated to the antibody-cytokine fusion protein through a flexible spacer $\mathrm{PEG}_{3400}$ in an attempt to retain its biological activity [41,47]. The loading of antibody is $0.25 \%$ to ensure each polymer chain has one antibody-cytokine fusion protein for biorecognition and immunotherapy. After 3'-modification with 2-pyridyldithiopropionate, $\alpha 4$ and $\beta 1$ AONs (designed to knock down the expression of both human and mouse laminin-411) were conjugated to the PMLA backbone via disulfide bond formation, which is cleavable in cytoplasm by glutathione after the nanobioconjugate escapes from endosome [41,47]. Unreacted sulfhydryl groups on PMLA backbone were blocked with 2-

pyridyldithiopropionate. The nanobioconjugate was purified with Sephadex G-75 column (GE Healthcare) using PBS as the solvent. Alternatively, nanobioconjugates that were used for imaging were fluorescently labeled with Alexa Fluor $680 \mathrm{C}_{2}$ maleimide or Alexa Fluor $488 \mathrm{C}_{5}$ maleimide by forming thioether with sulfhydryl groups, respectively. A schematic representation of the new PMLA nanobioconjugate is shown in Fig. 1C. The synthesis of the nanobioconjugate was monitored by size exclusion high-performance liquid chromatography (HPLC). The total amount of malic acid was determined with malate dehydrogenase assay [48]. The total amount of loaded fusion antibody was estimated with MicroBCA protein assay (Thermo Fisher Scientific). A colorimetric assay was used to determine the loading of $\mathrm{mPEG}$ as previously described [49]. The loaded amount of AON was estimated with reverse phase HPLC after reductive cleavage of AON from the nanobioconjugate using known concentrations of $\mathrm{AON}$ as standard. The entire P/mPEG/ LOEt/IgG3-(IL-2)/AON(a4 $\beta 1)$ nanobioconjugate is referred to as the lead PMLA-fusion nanobioconjugate. 


\subsection{Detection of HER2/neu and laminin- $\alpha 4$ and $\beta 1$ expressions by western blot}

Western blot analysis was performed as previously described [41,50]. Proteins were detected using the following primary monoclonal antibodies: mouse anti-laminin a4 (clone 8F12; a gift from Dr. Sekiguchi, Department of Biological Sciences, Osaka University, Osaka, Japan), rat anti-laminin $\beta 1$ (Abcam, Cambridge, MA) and mouse anti-human HER2/neu (Cell Signaling Technology, Inc., Danvers, MA). Rabbit anti-glyceraldehyde 3-phosphate dehydrogenase (GAPDH, Cell Signaling Technology, Inc.) was used as a loading control. All four primary antibodies cross-react with both mouse and human proteins. The ImmuneStar chemiluminescent kit (Bio-Rad Laboratories, Inc., Hercules, CA) was used as the substrate.

\subsection{HER2/neu binding of the PMLA-fusion nanobioconjugate (flow cytometry)}

Two hundred fifty thousand D2F2/E2 murine mammary cancer cells expressing human HER2/neu were incubated at $4{ }^{\circ} \mathrm{C}$ for $4 \mathrm{~h}$ in the presence of $2 \mu \mathrm{g} / \mathrm{ml}$ of PMLA-fusion nanobioconjugate or the equivalent amount of anti-HER2/neu IgG3-(IL-2) or anti-HER2/neu $\operatorname{IgG} 3$ followed by a 1-hour incubation with rabbit anti-human $\kappa$ antibody conjugated to FITC (BD Biosciences, San Jose, CA). Samples were analyzed on a Becton Dickinson FACScan ${ }^{\mathrm{TM}}$ Flow Cytometer in the UCLA Jonsson Comprehensive Cancer Center and Center for AIDS Research Flow Cytometry Core Facility. Histograms were created using the FCS Express V3 software (De Novo Software, Los Angeles, CA).

\subsection{IL-2 activity (proliferation assays)}

Murine CTLL-2 T-cells that are dependent on IL-2 for growth, were cultured in RPMI 1640 (Invitrogen) supplemented with $100 \mathrm{U} / \mathrm{ml}$ penicillin, $10 \mu \mathrm{g} / \mathrm{ml}$ streptomycin, and $10 \%$ and $10 \mathrm{U} / \mathrm{ml}$ of recombinant human IL-2 (PeproTech, Rocky Hill, NJ) for five days. After washing five times with RPMI 1640, cells were incubated in 96-well plates $\left(2 ! 10^{4}\right.$ cells/ well) for $18 \mathrm{~h}$ at $37{ }^{\circ} \mathrm{C}, 5 \% \mathrm{CO}_{2}$ in the presence of an equivalent molar amount of PMLAfusion nanobioconjugate, anti-HER2/neu IgG3, or anti-HER2/neu IgG3-(IL-2), serially diluted 3-fold over a range from 0.13 to $30 \mathrm{ng} / \mathrm{ml}$. Proliferation was measured by $\left[{ }^{3} \mathrm{H}\right]$ thymidine incorporation assay as previously described [51]. Cells were treated in quadruplicate for $18 \mathrm{~h}$ followed by a 6-hour pulse with $\left[{ }^{3} \mathrm{H}\right]$-thymidine (MP Biomedicals, Solon, $\mathrm{OH})$.

\subsection{In vitro cellular internalization (confocal microscopy)}

The human breast cancer cell line BT-474 overexpressing human HER2/neu was incubated in the presence of Alexa Fluor 488-labeled PMLA nanobioconjugate with or without fusion anti-HER2/neu IgG3-(IL-2) (maximum excitation/emission wavelength: 488/519 nm). After incubation for $2 \mathrm{~min}, 30 \mathrm{~min}$, and $1 \mathrm{~h}$, the cells were washed with PBS and fixed with 4\% paraformaldehyde. A TCS SP spectral scanner (Leica Microsystems, Mannheim, Germany) was used for confocal microscopy.

\subsection{In vivo biodistribution of PMLA-fusion nanobioconjugate}

One million BT-474 human breast cancer cells were implanted into the right flank of athymic mice (CrTac:NCr-Foxn1nu Homozygous, Taconic, Hudson, NY). When tumors reached $120 \mathrm{~mm}^{3}$ (about 21 days after tumor implantation), $150 \mu 1$ of Alexa Fluor 680 labeled PMLA copolymer, antibody-cytokine fusion protein or the PMLA-fusion nanobioconjugate was injected intravenously (i.v.) at the concentration of $10 \mu \mathrm{M}$ Alexa Fluor 680. For assessment of drug distribution and localization in nude mice, Xenogen IVIS 200 (STTARR, Toronto, ON, Canada) was used under isoflurane anesthesia at different time points (before drug administration, 1, 3, 6, and $24 \mathrm{~h}$ after injection of the drug). Twenty-four hours after drug administration, the mice were euthanized and the circulating drugs in blood 
vessels were eliminated by intra-arterial PBS perfusion. Tumors were harvested to detect the fluorescent signal. The fluorescent signal intensities in the tumors were analyzed by Xenogen Living Image ${ }^{\circledR}$, Version 2.50. All animal procedures were carried out in accordance with IACUC protocols approved by animal welfare committees at Cedars-Sinai Medical Center and UCLA.

\subsection{In vivo efficacy studies in a syngeneic breast cancer model}

D2F2/E2 cells were harvested using 0.5 mM EDTA in PBS and resuspended in Hank's balance salt solution (HBSS). Immunocompetent BALB/c mice were injected subcutaneously (s.c.) with $10^{6}$ tumor cells on day 0 . On days 6 and 8 , mice were systemically treated by i.v. injection with either $10 \mu \mathrm{g}$ of anti-HER2/neu IgG3-(IL-2) or the molar equivalent amount of PMLA-fusion nanobioconjugate. Control animals were injected with buffer (PBS). Tumor growth was monitored with a caliper and the volume calculated using the formula: tumor volume $=\left(\right.$ length $\times$ width $\left.^{2}\right) / 2$ [52], and survival considered as the period of time from tumor challenge until the tumor diameter reaches $1.5 \mathrm{~cm}$ when mice were euthanized.

\subsection{Assessment of murine anti-(ECD $\left.{ }^{\mathrm{HER} 2}\right)$ antibodies in serum}

Blood samples from animals in the in vivo efficacy studies were taken on day 27 . The level of murine anti-(ECD $\left.{ }^{\mathrm{HER} 2}\right) \mathrm{IgG} 1$ and $\mathrm{IgG} 2 \mathrm{a}$ was determined in pooled serum as described previously [29].

\section{Results}

\subsection{Characteristics of PMLA-fusion nanobioconjugate}

The PMLA-fusion nanobioconjugate (Fig. 1C) contains multiple components for the combination therapy of anti-angiogenesis and immunotherapy for breast cancer treatment. PMLA is biodegradable and nontoxic (its final degradation products are $\mathrm{H}_{2} \mathrm{O}$ and $\mathrm{CO}_{2}$ ), being completely suitable for drug delivery. In addition, its abundant carboxylate side chains are versatile for chemical modification for the attachment of antibodies, peptides, oligonucleotides, PEG, fluorophores, chemotherapeutic drugs, or other anti-cancer agents $[41,47,50,53,54]$. Each component in this nanobioconjugate plays a key role in its anticancer activity. Leucine ethyl ester is used for endosomal escape to ensure successful cytoplasmic delivery of AONs, since PMLA containing 40\% leucine ethyl ester is membrane disruptive $[41,55,56]$ through a membrane permeation mechanism distinctly described as a "carpet" model [56]. Anti-HER2/neu IgG3-(IL-2) functions as both a targeting molecule and as an immunostimulator. AON targeting laminin- 411 a 4 and $\beta 1$ chains are designed to effectively inhibit the synthesis of laminin-411, thus, suppressing tumor angiogenesis.

The size of nanobioconjugate was estimated to be around $27 \mathrm{~nm}$ by Zetasizer Nano ZS-90 (Malvern Instruments, Malvern, UK). The amount of malic acid, antibody-cytokine fusion protein, $\mathrm{mPEG}_{5000}$, and $\mathrm{AON}$ was determined using the method mentioned in Materials and methods and the loading of each component was calculated by the ratio of each component compared to total malic acid. The nanobioconjugate was estimated to contain $0.25 \%$ antibody and 5\% mPEG similar to the feed ratio. The total content of Morpholino was estimated to be $2.5 \%$ by reverse phase HPLC analysis of free Morpholino AON after the DTT reduction. Based on the measured amount of each component, the total molecular weight of the nanobioconjugate is calculated as $600 \mathrm{kDa}$. 


\subsection{Biorecognition and biological activity of nanobioconjugate}

Expression of HER2/neu, laminin a4, and laminin $\beta 1$ chains in D2F2/E2 cells was confirmed by western blot analysis (Fig. 2A). The specific biorecognition of HER2/neu by IgG3-(IL-2) after conjugation to PMLA-fusion nanobioconjugate was examined by flow cytometry. The PMLA-fusion nanobioconjugate retained the ability to bind to HER2/neu on the surface of D2F2/E2 murine mammary cancer cells expressing human HER2/neu and SK-BR-3 human breast cancer cells (Fig. 2B). The binding level of the nanobioconjugate was similar to both IgG3-(IL-2) and anti-HER2/neu IgG3 alone, suggesting that IgG3-(IL-2) conjugated to PMLA retained the HER2/neu targeting properties of the antibody. As expected, binding to D2F2 cells that do not express human HER2/neu was not detected (data not shown) suggesting that the biorecognition of the nanobioconjugate is specific to HER2/ neu.

To evaluate the biological activity of the IL-2 present in the nanobioconjugate we measured its ability to sustain the proliferation of murine CTLL-2 T-cell clonal cell line that is dependent on IL-2 for expansion. The nanobioconjugate elicits similar levels of $\left[{ }^{3} \mathrm{H}\right]-$ thymidine incorporation compared with the anti-HER2/neu IgG3-(IL-2) alone. As expected the IgG3 antibody alone or buffer control did not show any activity in this assay (Fig. 3). These results indicate that the biological activity of IL-2 within the antibody-cytokine fusion protein was retained after being conjugated to the PMLA copolymer.

\subsection{Cellular uptake and in vivo tumor targeting of the PMLA-fusion nanobioconjugate}

The BT-474 human breast cancer cell line expresses high levels of HER2/neu (Fig. 2A). Specific cellular uptake of the PMLA-fusion nanobioconjugate through HER2/neu was visualized by confocal microscopy. A PMLA copolymer without anti-HER2/neu IgG3(IL-2) showed only a weak intracellular signal after $1 \mathrm{~h}$ (Fig. 4A, upper panel). In contrast, the PMLA-fusion nanobioconjugate with anti-HER2/neu IgG3-(IL-2) was detected on the cell surface and in the cytoplasm within $2 \mathrm{~min}$ and the signal was the strongest after $60 \mathrm{~min}$ (Fig. 4A, lower panel). These results suggest that conjugation of anti-HER2/neu IgG3-(IL-2) to PMLA allows both the cell surface binding and the cellular uptake of the resulting nanobioconjugate. When nanobioconjugate is delivered into the cells the AONs escape from the endosomes by leucine ethyl ester as an endosomal escape unit. AONs are cleaved in the cytoplasm of cancer cells by intracellular glutathione and block the synthesis laminin- 411 .

In vivo imaging studies showed tumor targeting of the PMLA-fusion nanobioconjugate. Six hours after injection, only Alexa Fluor 680 labeled P/mPEG/LOEt/IgG3-(IL-2) [the PMLAfusion nanobioconjugate minus the $\mathrm{AON}$ ] showed strong accumulation at the tumor site in the whole body imaging analysis of treated mice (Fig. 4B, left panel). Another signal corresponding to the liver was also observed in these animals. This is expected since nanoparticles are known to accumulate in the liver [57]. Weak accumulation of P/mPEG/ LOEt [the PMLA-fusion nanobioconjugate minus the AON and the anti-HER2/neu IgG3(IL-2)] at the tumor site is probably a result of the non-specific enhanced permeability and retention (EPR) effect of nanoparticles [58]. Tumor targeting remained evident $24 \mathrm{~h}$ after treatment in excised tumors (Fig. 4B, right panel).

\subsection{Treatment of syngeneic mammary tumor with PMLA-fusion nanobioconjugate with simultaneous activation of adaptive and innate immune responses}

The anti-tumor activity of PMLA-fusion nanobioconjugate was initially evaluated using a syngeneic mouse model using D2F2/E2 murine mammary cancer cells that express human HER2/neu. Only the treatment with the PMLA-fusion nanobioconjugate, but not IgG3(IL-2) significantly improved the survival of mice bearing mam-mary tumors compared to mice treated with buffer alone (Fig. 5). Additionally, the PMLA-fusion nanobioconjugate 
was well tolerated. In order to explore immunoactivation as a potential mechanism that may contribute to anti-cancer activity of PMLA-fusion nanobioconjugate, serum from treated mice was collected, pooled and analyzed for the presence of murine anti-HER2/neu antibodies. The presence of murine anti-HER $2 /$ neu $\operatorname{IgG} 1$ in serum of treated animals is indicative of the induction of a humoral $\left(\mathrm{T}_{\mathrm{H}} 2\right)$ immune response, while the presence of murine anti-HER2/neu IgG2a antibodies suggests the induction of a cell-mediated $\left(\mathrm{T}_{\mathrm{H}} 1\right)$ immune response [29,59]. Both IgG1 and IgG2a levels were significantly increased in animals treated with the PMLA-fusion nanobioconjugate compared to animals treated with the antibody-cytokine fusion protein alone or buffer control animals (Fig. 6).

\section{Discussion}

We have previously established an efficient drug delivery system Polycefin ${ }^{\mathrm{TM}}$ using PMLA as a platform and have shown that nanobioconjugates composed of various anti-cancer agents can specifically target cancer cells and inhibit breast and brain tumor growth and angiogenesis $[39,50]$. PMLA-based nanobioconjugates overcome drawbacks of conventional chemotherapy by their ability to incorporate multiple drug combinations on a single platform and thus, more adequately target the tumor. We have now further modified the PMLA-based nanobioconjugate in an attempt to design a potential new therapeutic for HER2/neu-positive breast cancer and possibly overcome some of the hurdles of trastuzumab resistance.

Multi-functional nanobioconjugates are capable of targeting several oncogenic pathways resulting in a superior therapeutic effect compared to each drug alone. The new PMLAbased nanobioconjugate described here contains an antibody-cytokine fusion protein that serves to add two additional functions to our previous nanobioconjugates. First, tumor targeting through HER2/neu may also inhibit the proliferation of human cancer cells since the anti-HER2/neu IgG3-(IL-2) contains the variable regions of trastuzumab. Second, the antibody-cytokine fusion protein localizes IL-2 within the tumor microenvironment. This is expected to decrease the toxic side effects of high-dose systemic cytokine administration and enhance the immune response against the targeted cancer cells. In addition, the EPR effect of the nanobioconjugate may further enhance the tumor targeting. Moreover, the PMLA-fusion nanobioconjugate described here features AON against laminin-411 a4 and $\beta 1$ chains, which are expressed by many cancer cells including BT-474, to suppress tumor angiogenesis. Therefore, the described PMLA-fusion nanobioconjugate provides a multipronged attack against the targeted cancer cells. It is expected that this will increase the tumor targeting ability of the nanobioconjugate resulting in enhanced anti-cancer activity with decreased potential side effects.

Synthesis of the PMLA-fusion nanobioconjugate required multiple steps and chemical reactions. It is important that the antibody-cytokine fusion protein did not lose its ability to bind the targeted antigen, HER2/neu, after its covalent conjugation to PMLA. Similarly it is also important that the bioactivity of IL-2 within the antibody-cytokine fusion protein was also retained within the PMLA-fusion nanobioconjugate. Our results demonstrate that the anti-HER2/neu IgG3-(IL-2) enhanced drug internalization into the HER2/neu overexpressing tumor cells. Therefore, the antibody-cytokine fusion protein retains its antigen binding and IL-2 bioactivity after covalent conjugation to PMLA. Furthermore, in vivo accumulation of the PMLA-fusion nanobioconjugate within the tumor area was significantly higher than that of PMLA copolymer without the antibody-cytokine fusion protein. This further confirms the successful conjugation of the fusion protein anti-HER2/ neu IgG3-(IL-2) to PMLA, similar to our previously published data using therapeutic antibodies [37]. 
Laminin-411 was previously identified as a critical angiogenic marker for breast cancer $[38,41,47]$. It is expressed both by the tumor cells and in the tumor neovasculature. We have achieved successful suppression of laminin-411 synthesis with Morpholino AON using PMLA-based nanobioconjugates. Here we found laminin-411 expression in the murine mammary cancer cell line D2F2/E2. Therefore, it is expected that the AONs block the synthesis of tumor vascular protein expression, laminin-411 in these cells.

In an initial anti-tumor study the PMLA-fusion nanobioconjugate demonstrated significant anti-tumor activity in vivo and showed an immunoactivation pattern consistent with this effect. This effect was observed despite the fact that only two treatments of the nanobioconjugate were administered. The effective in vivo treatment possibly resulted from simultaneous: 1 . Specific delivery of AONs to prevent synthesis of laminin-411;2. Blockage of the HER2/neu receptor; and 3. Activation of humoral and cellular immune responses. Interestingly, treatment with the PMLA-fusion nanobioconjugate significantly increased serum levels of murine anti-HER2/neu IgG1 and IgG2a, suggesting an enhancement of the humoral and cellular immune responses, consistent with the anti-tumor protection in mice treated with the nanobioconjugate. Further studies are needed to con-firm and improve the in vivo efficacy of the present nanobioconjugate and understand its in vivo mechanism of anti-cancer activity.

\section{Conclusion}

The PMLA-fusion nanobioconjugate described here represents a new generation of cancer therapeutics. The multifunctional PMLA-fusion nanobioconjugate consists of key components that facilitate its multi-pronged attack against cancer cells and their neovasculature including the induction of an anti-tumor immune response. For the first time, we have successfully incorporated an antibody-cytokine fusion protein into polymalic acidbased nanobioconjugate. Our data suggest that PMLA-based nanobioconjugates may make a significant clinical impact on the treatment of HER2/neu-positive malignancies.

\section{Acknowledgments}

This work was supported in part by NIH/NCI R01CA123495 and U01CA151815 (Julia Y. Ljubimova), R01CA136841 (Julia Y. Ljubimova and Manuel L. Penichet), and K01CA138559 (Tracy R. Daniels-Wells). This work was also supported by the UC MEXUS-CONACYT Fellowship Program, the Howard Hughes Medical Institute Gilliam Fellowship, the Whitcome Fellowship of the Molecular Biology Institute at UCLA, the ANPCyTFONARSEC PICT-PRH 2008-00315, the CONICET PIP no. 114-2011-01-00139, and the UBACYT no. 200-2011-02-00027. Gustavo Helguera is a member of the National Council for Scientific and Technological Research (CONICET), Argentina. The UCLA JCCC Flow Cytometry Core Facility is supported by the NIH Awards CA16042 and AI28697, the Jonsson Cancer Center, the UCLA AIDS Institute and the UCLA School of Medicine.

\section{References}

[1]. Siegel R, Naishadham D, Jemal A. Cancer statistics, 2013. CA Cancer J. Clin. 2013; 63(1):11-30. [PubMed: 23335087]

[2]. Slamon DJ, Clark GM, Wong SG, Levin WJ, Ullrich A, McGuire WL. Human breast cancer: correlation of relapse and survival with amplification of the HER-2/neu oncogene. Science. 1987; 235(4785):177-182. [PubMed: 3798106]

[3]. Slamon DJ, Godolphin W, Jones LA, Holt JA, Wong SG, Keith DE, Levin WJ, Stuart SG, Udove J, Ullrich A, et al. Studies of the HER-2/neu proto-oncogene in human breast and ovarian cancer. Science. 1989; 244(4905):707-712. [PubMed: 2470152]

[4]. Press MF, Pike MC, Hung G, Zhou JY, Ma Y, George J, Dietz-Band J, James W, Slamon DJ, Batsakis JG, et al. Amplification and overexpression of HER-2/neu in carcinomas of the salivary 
gland: correlation with poor prognosis. Cancer Res. 1994; 54(21):5675-5682. [PubMed: 7522962]

[5]. Haffty BG, Brown F, Carter D, Flynn S. Evaluation of HER-2 neu oncoprotein expression as a prognostic indicator of local recurrence in conservatively treated breast cancer: a case-control study. Int. J. Radiat. Oncol. Biol. Phys. 1996; 35(4):751-757. [PubMed: 8690641]

[6]. Nahta R, Esteva FJ. Trastuzumab: triumphs and tribulations. Oncogene. 2007; 26(25):3637-3643. [PubMed: 17530017]

[7]. Pegram MD, Pienkowski T, Northfelt DW, Eiermann W, Patel R, Fumoleau P, Quan E, Crown J, Toppmeyer D, Smylie M, Riva A, Blitz S, Press MF, Reese D, Lindsay MA, Slamon DJ. Results of two open-label, multicenter phase II studies of docetaxel, platinum salts, and trastuzumab in HER2-positive advanced breast cancer. J. Natl. Cancer Inst. 2004; 96(10):759-769. [PubMed: 15150304]

[8]. Slamon DJ, Leyland-Jones B, Shak S, Fuchs H, Paton V, Bajamonde A, Fleming T, Eiermann W, Wolter J, Pegram M, Baselga J, Norton L. Use of chemotherapy plus a monoclonal antibody against HER2 for metastatic breast cancer that overexpresses HER2. N. Engl. J. Med. 2001; 344(11):783-792. [PubMed: 11248153]

[9]. Vogel CL, Cobleigh MA, Tripathy D, Gutheil JC, Harris LN, Fehrenbacher L, Slamon DJ, Murphy M, Novotny WF, Burchmore M, Shak S, Stewart SJ. First-line Herceptin monotherapy in metastatic breast cancer. Oncology. 2001; 61(Suppl. 2):37-42. [PubMed: 11694786]

[10]. Vogel CL, Cobleigh MA, Tripathy D, Gutheil JC, Harris LN, Fehrenbacher L, Slamon DJ, Murphy M, Novotny WF, Burchmore M, Shak S, Stewart SJ, Press M. Efficacy and safety of trastuzumab as a single agent in first-line treatment of HER2-overexpressing metastatic breast cancer. J. Clin. Oncol. 2002; 20(3):719-726. [PubMed: 11821453]

[11]. Baselga J, Tripathy D, Mendelsohn J, Baughman S, Benz CC, Dantis L, Sklarin NT, Seidman AD, Hudis CA, Moore J, Rosen PP, Twaddell T, Henderson IC, Norton L. Phase II study of weekly intravenous trastuzumab (Herceptin) in patients with HER2/neu-overexpressing metastatic breast cancer. Semin. Oncol. 1999; 26(4 Suppl. 12):78-83. [PubMed: 10482197]

[12]. Wang YC, Morrison G, Gillihan R, Guo J, Ward RM, Fu X, Botero MF, Healy NA, Hilsenbeck SG, Phillips GL, Chamness GC, Rimawi MF, Osborne CK, Schiff R. Different mechanisms for resistance to trastuzumab versus lapatinib in HER2-positive breast cancers - role of estrogen receptor and HER2 reactivation. Breast Cancer Res. 2011; 13(6):R121. [PubMed: 22123186]

[13]. Brandes AA, Franceschi E, Tosoni A, Degli Esposti R. Trastuzumab and lapatinib beyond trastuzumab progression for metastatic breast cancer: strategies and pitfalls. Expert Rev. Anticancer Ther. 2010; 10(2):179-184. [PubMed: 20131994]

[14]. Markman B, Tabernero J. Monoclonal antibodies in solid tumours. Curr. Clin. Pharmacol. 2010

[15]. Nahta R, Esteva FJ. Herceptin: mechanisms of action and resistance. Cancer Lett. 2006; 232(2): 123-138. [PubMed: 16458110]

[16]. Whittington R, Faulds D. Interleukin-2. A review of its pharmacological properties and therapeutic use in patients with cancer. Drugs. 1993; 46(3):446-514. [PubMed: 7693434]

[17]. Negrier S, Maral J, Drevon M, Vinke J, Escudier B, Philip T. Long-term follow-up of patients with metastatic renal cell carcinoma treated with intravenous recombinant interleukin-2 in Europe. Cancer J. Sci. Am. 2000; 6(Suppl. 1):S93-S98. [PubMed: 10685667]

[18]. Siegel JP, Puri RK. Interleukin-2 toxicity. J. Clin. Oncol. 1991; 9(4):694-704. [PubMed: 2066765]

[19]. Rosenberg SA, Lotze MT, Yang JC, Aebersold PM, Linehan WM, Seipp CA, White DE. Experience with the use of high-dose interleukin-2 in the treatment of 652 cancer patients. Ann. Surg. 1989; 210(4):474-484. discussion 484-475. [PubMed: 2679456]

[20]. Helguera G, Morrison SL, Penichet ML. Antibody-cytokine fusion proteins: harnessing the combined power of cytokines and antibodies for cancer therapy. Clin. Immunol. 2002; 105(3): 233-246. [PubMed: 12498805]

[21]. Ortiz-Sanchez E, Helguera G, Daniels TR, Penichet ML. Antibody-cytokine fusion proteins: applications in cancer therapy. Expert Opin. Biol. Ther. 2008; 8(5):609-632. [PubMed: 18407765] 
[22]. Penichet ML, Dela Cruz JS, Shin SU, Morrison SL. A recombinant IgG3-(IL-2) fusion protein for the treatment of human HER2/neu expressing tumors. Hum. Antibodies. 2001; 10(1):43-49. [PubMed: 11455061]

[23]. Phillips ML, Tao MH, Morrison SL, Schumaker VN. Human/mouse chimeric monoclonal antibodies with human IgG1, IgG2, IgG3 and IgG4 constant domains: electron microscopic and hydrodynamic characterization. Mol. Immunol. 1994; 31(15):1201-1210. [PubMed: 7935507]

[24]. Hiltbold EM, Vlad AM, Ciborowski P, Watkins SC, Finn OJ. The mechanism of unresponsiveness to circulating tumor antigen MUC1 is a block in intracellular sorting and processing by dendritic cells. J. Immunol. 2000; 165(7):3730-3741. [PubMed: 11034378]

[25]. Dela Cruz JS, Trinh KR, Chen HW, Ribas A, Morrison SL, Penichet ML. Anti-HER2/neu IgG3(IL-2) and anti-HER2/neu IgG3-(GM-CSF) promote HER2/neu processing and presentation by dendritic cells: implications in immunotherapy and vaccination strategies. Mol. Immunol. 2006; 43(6):667-676. [PubMed: 15908002]

[26]. Helguera G, Rodriguez JA, Penichet ML. Cytokines fused to antibodies and their combinations as therapeutic agents against different peritoneal HER2/neu expressing tumors. Mol. Cancer Ther. 2006; 5(4):1029-1040. [PubMed: 16648575]

[27]. Dela Cruz JS, Lau SY, Ramirez EM, De Giovanni C, Forni G, Morrison SL, Penichet ML. Protein vaccination with the HER2/neu extracellular domain plus anti-HER2/neu antibodycytokine fusion proteins induces a protective anti-HER2/neu immune response in mice. Vaccine. 2003; 21(13-14):1317-1326. [PubMed: 12615426]

[28]. Dela Cruz JS, Morrison SL, Penichet ML. Insights into the mechanism of anti-tumor immunity in mice vaccinated with the human HER2/neu extracellular domain plus anti-HER2/neu IgG3(IL-2) or anti-HER2/neu IgG3-(GM-CSF) fusion protein. Vaccine. 2005; 23(39):4793-4803. [PubMed: 15967544]

[29]. Helguera G, Dela Cruz JS, Lowe C, Ng PP, Trinh R, Morrison SL, Penichet ML. Vaccination with novel combinations of anti-HER2/neu cytokines fusion proteins and soluble protein antigen elicits a protective immune response against HER2/neu expressing tumors. Vaccine. 2006; 24(3): 304-316. [PubMed: 16125282]

[30]. Esteva FJ, Valero V, Booser D, Guerra LT, Murray JL, Pusztai L, Cristofanilli M, Arun B, Esmaeli B, Fritsche HA, Sneige N, Smith TL, Hortobagyi GN. Phase II study of weekly docetaxel and trastuzumab for patients with HER-2-overexpressing metastatic breast cancer. J. Clin. Oncol. 2002; 20(7):1800-1808. [PubMed: 11919237]

[31]. Seidman AD, Fornier MN, Esteva FJ, Tan L, Kaptain S, Bach A, Panageas KS, Arroyo C, Valero V, Currie V, Gilewski T, Theodoulou M, Moynahan ME, Moasser M, Sklarin N, Dickler M, D'Andrea G, Cristofanilli M, Rivera E, Hortobagyi GN, Norton L, Hudis CA. Weekly trastuzumab and paclitaxel therapy for metastatic breast cancer with analysis of efficacy by HER2 immunophenotype and gene amplification. J. Clin. Oncol. 2001; 19(10):2587-2595. [PubMed: 11352950]

[32]. Reisfeld RA. The tumor microenvironment: a target for combination therapy of breast cancer. Crit. Rev. Oncog. 2013; 18(1-2):115-133. [PubMed: 23237555]

[33]. Fujiwara H, Kikkawa Y, Sanzen N, Sekiguchi K. Purification and characterization of human laminin-8. Laminin-8 stimulates cell adhesion and migration through alpha3beta1 and alpha6beta1 integrins. J. Biol. Chem. 2001; 276(20):17550-17558. [PubMed: 11278628]

[34]. Thyboll J, Kortesmaa J, Cao R, Soininen R, Wang L, Iivanainen A, Sorokin L, Risling M, Cao Y, Tryggvason K. Deletion of the laminin alpha4 chain leads to impaired microvessel maturation. Mol. Cell. Biol. 2002; 22(4):1194-1202. [PubMed: 11809810]

[35]. Patarroyo M, Tryggvason K, Virtanen I. Laminin isoforms in tumor invasion, angiogenesis and metastasis. Semin. Cancer Biol. 2002; 12(3):197-207. [PubMed: 12083850]

[36]. Gonzalez AM, Gonzales M, Herron GS, Nagavarapu U, Hopkinson SB, Tsuruta D, Jones JC. Complex interactions between the laminin alpha 4 subunit and integrins regulate endothelial cell behavior in vitro and angiogenesis in vivo. Proc. Natl. Acad. Sci. U. S. A. 2002; 99(25):1607516080. [PubMed: 12454288]

[37]. Fujita M, Khazenzon NM, Bose S, Sekiguchi K, Sasaki T, Carter WG, Ljubimov AV, Black KL, Ljubimova JY. Overexpression of beta1-chain-containing laminins in capillary basement 
membranes of human breast cancer and its metastases. Breast Cancer Res. 2005; 7(4):R411R421. [PubMed: 15987446]

[38]. Fujita M, Khazenzon NM, Ljubimov AV, Lee BS, Virtanen I, Holler E, Black KL, Ljubimova JY. Inhibition of laminin-8 in vivo using a novel poly(malic acid)-based carrier reduces glioma angiogenesis. Angiogenesis. 2006; 9(4):183-191. [PubMed: 17109197]

[39]. Fujita M, Lee BS, Khazenzon NM, Penichet ML, Wawrowsky KA, Patil R, Ding H, Holler E, Black KL, Ljubimova JY. Brain tumor tandem targeting using a combination of monoclonal antibodies attached to biopoly(beta-1-malic acid). J. Control. Release. 2007; 122(3):356-363. [PubMed: 17630012]

[40]. Ljubimova JY, Fugita M, Khazenzon NM, Das A, Pikul BB, Newman D, Sekiguchi K, Sorokin LM, Sasaki T, Black KL. Association between laminin-8 and glial tumor grade, recurrence, and patient survival. Cancer. 2004; 101(3):604-612. [PubMed: 15274074]

[41]. Ding H, Inoue S, Ljubimov AV, Patil R, Portilla-Arias J, Hu J, Konda B, Wawrowsky KA, Fujita M, Karabalin N, Sasaki T, Black KL, Holler E, Ljubimova JY. Inhibition of brain tumor growth by intravenous poly (beta-l-malic acid) nanobioconjugate with $\mathrm{pH}$-dependent drug release [corrected]. Proc. Natl. Acad. Sci. U. S. A. 2010; 107(42):18143-18148. [PubMed: 20921419]

[42]. Braud C, Vert M. Degradation of poly(p-malic acid) - monitoring of oligomers formation by aqueous SEC and HPCE. Polym. Bull. 1992; 29:177-183.

[43]. Gasslmaier B, Krell CM, Seebach D, Holler E. Synthetic substrates and inhibitors of beta-poly(1malate)-hydrolase (polymalatase). Eur. J. Biochem. 2000; 267(16):5101-5105. [PubMed: 10931193]

[44]. Lee, B-S.; Vert, M.; Holler, E. Biopolymers. Doi, YSA., editor. Wiley-VCH; Weinheim: 2002. p. 75-103.

[45]. Wei WZ, Shi WP, Galy A, Lichlyter D, Hernandez S, Groner B, Heilbrun L, Jones RF. Protection against mammary tumor growth by vaccination with full-length, modified human ErbB-2 DNA. Int. J. Cancer. 1999; 81(5):748-754. [PubMed: 10328228]

[46]. Helguera G, Penichet ML. Antibody-cytokine fusion proteins for the therapy of cancer. Methods Mol. Med. 2005; 109:347-374. [PubMed: 15585931]

[47]. Lee BS, Fujita M, Khazenzon NM, Wawrowsky KA, Wachsmann-Hogiu S, Farkas DL, Black KL, Ljubimova JY, Holler E. Polycefin, a new prototype of a multifunctional nanobioconjugate based on poly(beta-1-malic acid) for drug delivery. Bioconjug. Chem. 2006; 17(2):317-326. [PubMed: 16536461]

[48]. Lee, BS.; Vert, M.; Holler, E. Water-soluble Aliphatic Polyesters: Poly(malic acid)s. Wiley-VCH Verlag Gmbh; Weinheim: 2002.

[49]. Li S, Yang Z, Sun X, Tan Y, Yagi S, Hoffman RM. A simultaneous colorimetric assay of free and protein-coupled polyethylene glycol. Anal. Biochem. 2003; 313(2):335-337. [PubMed: 12605873]

[50]. Inoue S, Ding H, Portilla-Arias J, Hu J, Konda B, Fujita M, Espinoza A, Suhane S, Riley M, Gates M, Patil R, Penichet ML, Ljubimov AV, Black KL, Holler E, Ljubimova JY. Polymalic acid-based nanobiopolymer provides efficient systemic breast cancer treatment by inhibiting both HER2/neu receptor synthesis and activity. Cancer Res. 2011; 71(4):1454-1464. [PubMed: 21303974]

[51]. Daniels TR, Ng PP, Delgado T, Lynch MR, Schiller G, Helguera G, Penichet ML. Conjugation of an anti transferrin receptor IgG3-avidin fusion protein with biotinylated saporin results in significant enhancement of its cytotoxicity against malignant hematopoietic cells. Mol. Cancer Ther. 2007; 6(11):2995-3008. [PubMed: 18025284]

[52]. Carlsson G, Ekelund L, Stigsson L, Hafstrom L. Vascularization and tumour volume estimations of solitary liver tumours in rats. Ann. Chir. Gynaecol. 1983; 72(4):187-191. [PubMed: 6638901]

[53]. Ljubimova JY, Fujita M, Khazenzon NM, Lee BS, Wachsmann-Hogiu S, Farkas DL, Black KL, Holler E. Nanobioconjugate based on polymalic acid for tumor targeting. Chem. Biol. Interact. 2008; 171(2):195-203. [PubMed: 17376417]

[54]. Patil R, Portilla-Arias J, Ding H, Konda B, Rekechenetskiy A, Inoue S, Black KL, Holler E, Ljubimova JY. Cellular delivery of doxorubicin via $\mathrm{pH}$-controlled hydrazone linkage using 
multifunctional nano vehicle based on poly(beta-1-malic acid). Int. J. Mol. Sci. 2012; 13(9): 11681-11693. [PubMed: 23109877]

[55]. Ding H, Portilla-Arias J, Patil R, Black KL, Ljubimova JY, Holler E. The optimization of polymalic acid peptide copolymers for endosomolytic drug delivery. Biomaterials. 2011; 32(22): 5269-5278. [PubMed: 21514661]

[56]. Ding H, Portilla-Arias J, Patil R, Black KL, Ljubimova JY, Holler E. Distinct mechanisms of membrane permeation induced by two polymalic acid copolymers. Biomaterials. 2013; 34(1): 217-225. [PubMed: 23063368]

[57]. Minchin RF, Martin DJ. Nanoparticles for molecular imaging-an overview. Endocrinology. 2010; 151(2):474-481. [PubMed: 20016027]

[58]. Matsumura Y, Maeda H. A new concept for macromolecular therapeutics in cancer chemotherapy: mechanism of tumoritropic accumulation of proteins and the antitumor agent smancs. Cancer Res. 1986; 46(12 Pt 1):6387-6392. [PubMed: 2946403]

[59]. Stevens TL, Bossie A, Sanders VM, Fernandez-Botran R, Coffman RL, Mosmann TR, Vitetta ES. Regulation of antibody isotype secretion by subsets of antigen-specific helper T cells. Nature. 1988; 334(6179):255-258. [PubMed: 2456466] 

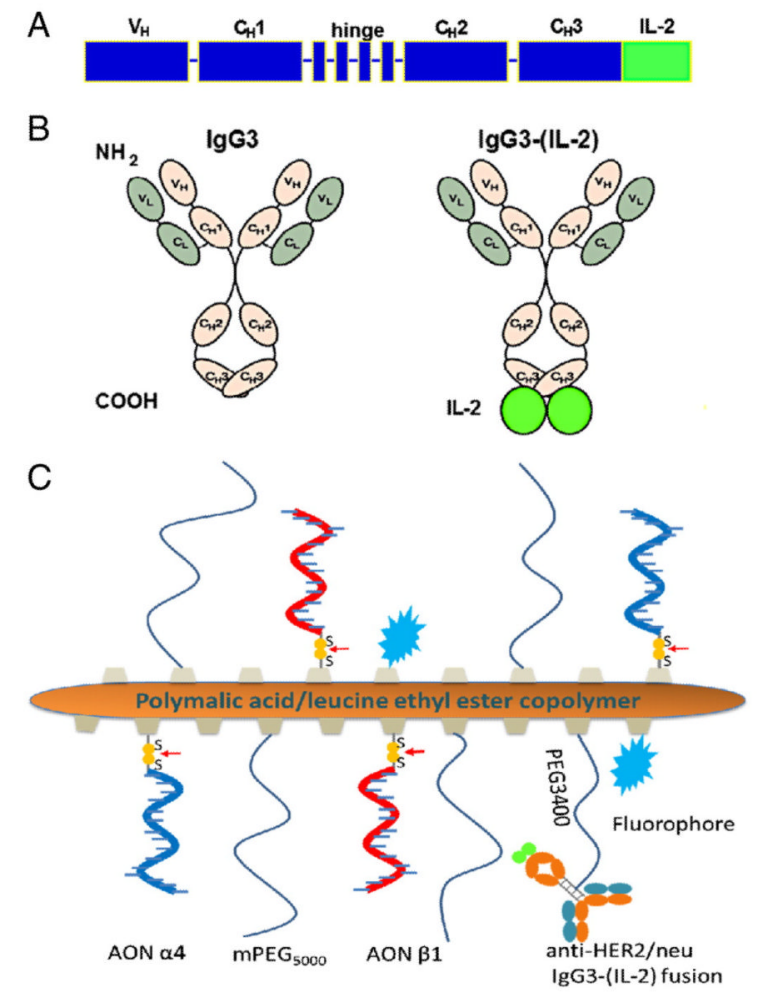

Fig. 1.

Schematic representations of anti-HER2/neu IgG3-(IL-2) and the PMLA-fusion nanobioconjugate. A) Scheme of genes encoding the heavy chain of the anti-HER2/neu IgG3 fusion protein. B) Schematic representation of anti-HER2/neu IgG3 (IgG3) and antiHER2/neu IgG3-(IL-2) antibody-cytokine fusion protein [IgG3-(IL-2)]. C) Schematic representation of PMLA-fusion nanobioconjugate [P/mPEG/LOEt/IgG3-(IL-2)/ $\mathrm{AON}(a 4 \beta 1)]$. 


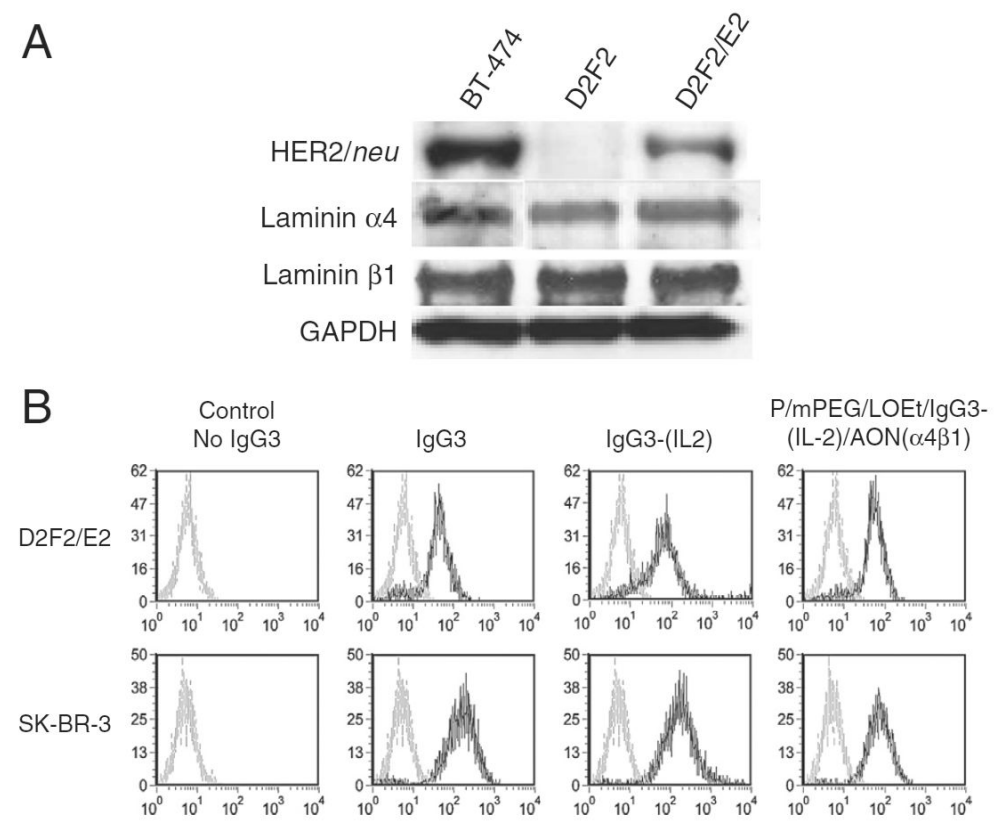

Fig. 2.

Expression level of anti-HER2/neu and the specific binding to human anti-HER2/neu. A) The expression of anti-HER2/neu, laminin $\alpha 4$, and $\beta 1$ chains in BT-474, D2F2, and D2F2/ E2 cell lines was detected by western blot analysis. Expression of GAPDH was used as a loading control. B) Binding of various molecules to D2F2/E2 (top) and SK-BR-3 (bottom) as determined by flow cytometry. Cell lines were incubated in control buffer (gray line) or in the presence of anti-HER2/neu IgG3, anti-HER2/neu IgG3-(IL-2), or P/mPEG/LOEt/ IgG3-(IL-2)/AON(a4ß1) (black line) all equivalent to $2 \mu \mathrm{g}$ of IgG3, followed by rabbit antihuman $\kappa$ conjugated to FITC. 


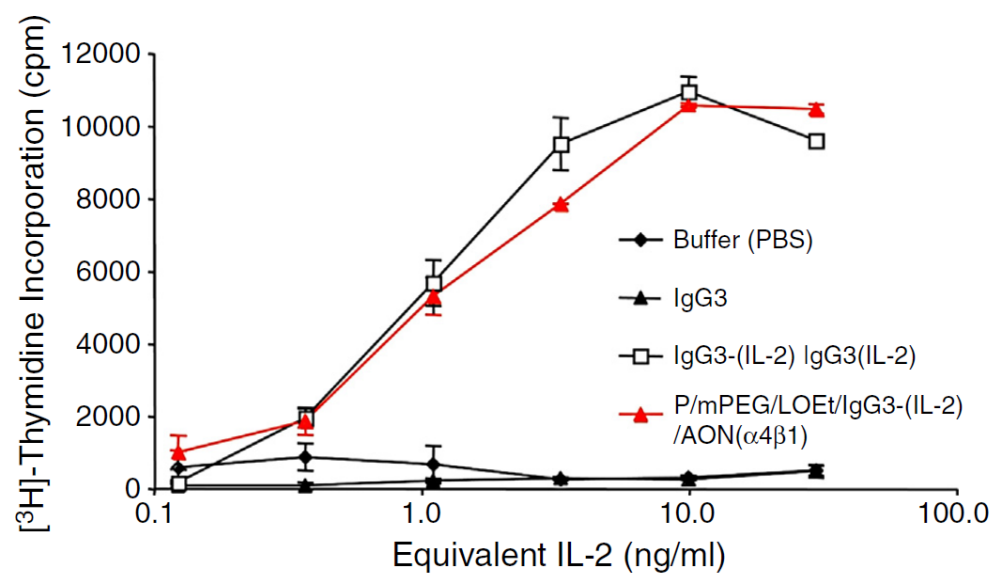

Fig. 3.

In vitro biologic activity of IL-2 within the PMLA-fusion nanobioconjugate. IL-2 activity was determined by incorporation of $\left[{ }^{3} \mathrm{H}\right]$-thymidine into CTLL-2 cells incubated in the presence of varying concentrations of IL-2 fusion proteins and controls. Serial 1:3 dilutions of IL-2 equivalents ranging from $30 \mathrm{ng} / \mathrm{ml}$ to $0.13 \mathrm{ng} / \mathrm{ml}$ of anti-HER2/neu IgG3 (IgG3), anti-HER2/nеи IgG3-(IL-2) [IgG3-(IL-2)], and PMLA-fusion nanobioconjugate P/mPEG/ LOEt/IgG3-(IL-2)/AON(a4ß1) were made in quadruplicate and incubated with CTLL-2 cells for $18 \mathrm{~h}$ followed by a 6-hour pulse of $\left[{ }^{3} \mathrm{H}\right]$-thymidine. The error bars indicate the standard deviation. 

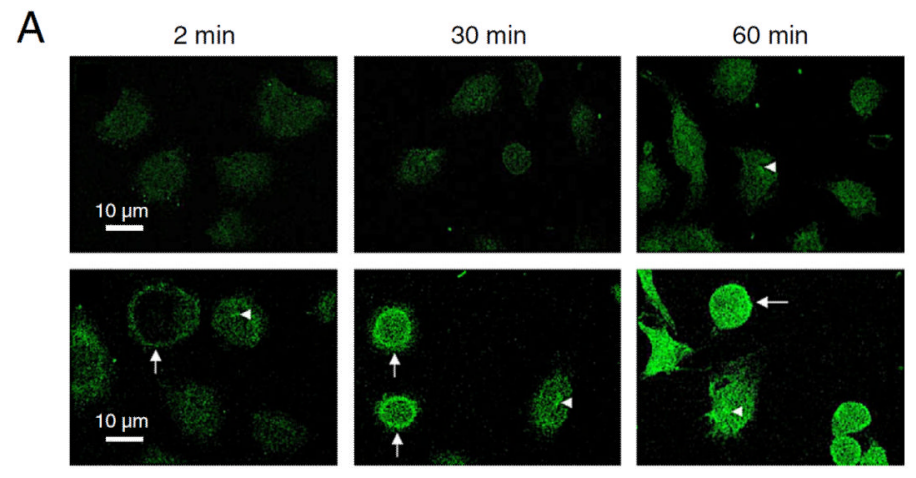

\section{B}
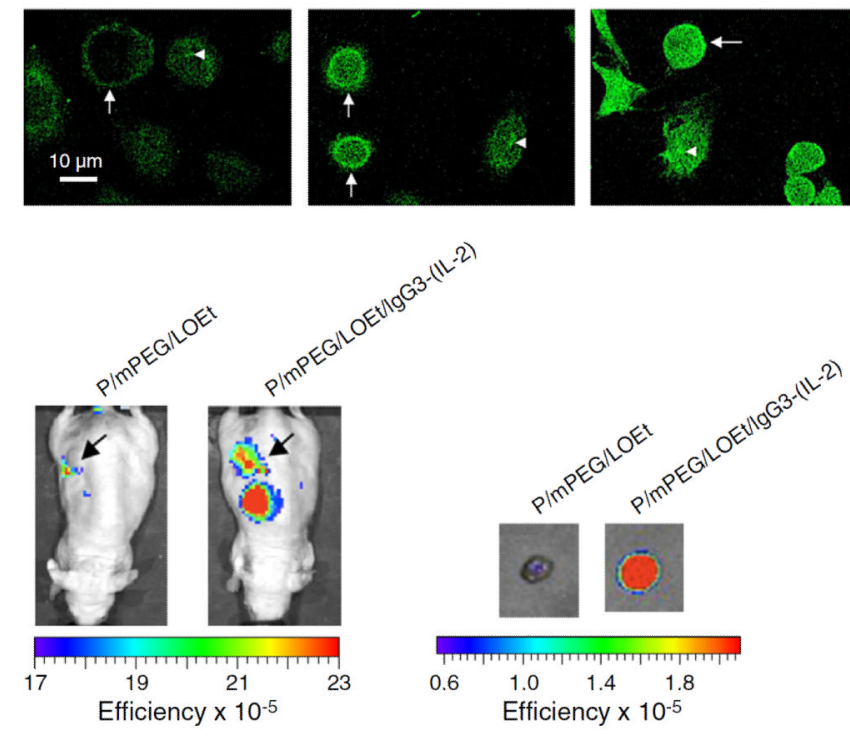

Fig. 4.

Visualization of breast cancer cell targeting in vitro and in vivo. A) Internalization of PMLA-fusion nanobioconjugate in breast cancer cells visualized by confocal microscopy ( $\times 40$ magnification). The human breast cancer cell line BT-474 expressing human antiHER2/neu was incubated in the presence of Alexa Fluor 488-labeled PMLA copolymer P/ mPEG/LOEt [without anti-HER2/neu IgG3-(IL-2) (upper panels)] or PMLA-fusion nanobioconjugate $\mathrm{P} / \mathrm{mPEG} / \mathrm{LOEt} / \mathrm{IgG} 3$-(IL-2) [lower panels]. The signal was detected in cells after $2 \mathrm{~min}, 30 \mathrm{~min}$, and $60 \mathrm{~min}$. The location of nanobioconjugate is indicated by green fluorescence near the cell membrane (arrows), and in the endosome compartment (arrowheads). B) Whole body imaging of mice $6 \mathrm{~h}$ after the injection of fluorescence labeled $\mathrm{P} / \mathrm{mPEG} / \mathrm{LOEt}$, and PMLA-fusion nanobioconjugate P/mPEG/LOEt/IgG3-(IL-2) [left panel]. Arrows mark tumor implantation site. Imaging of individual tumors extracted $24 \mathrm{~h}$ after treatment [right panel]. Images are representative of 4 animals. (For interpretation of the references to color in this figure legend, the reader is referred to the web version of this article.) 


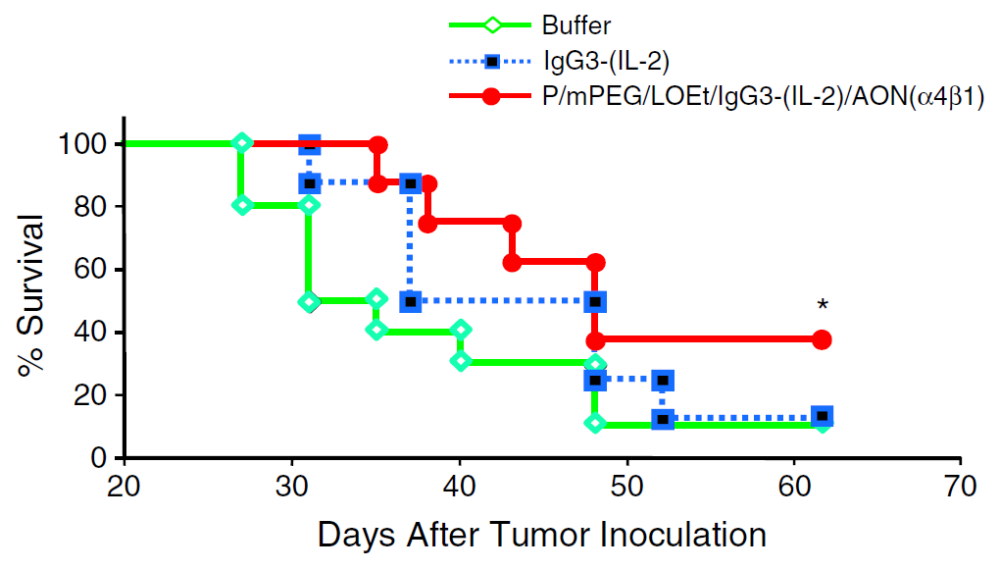

Fig. 5.

Anti-tumor activity of the PMLA-fusion nanobioconjugate in a murine syngeneic mammary tumor model. Animals bearing s.c. D2F2/E2 tumors received i.v. injections with either 10 $\mu \mathrm{g}$ of anti-HER2/neu IgG3-(IL-2) $(\mathrm{n}=8)$ or the equivalent molar amount of PMLA-fusion nanobioconjugate $(n=8)$ on days 6 and 8 . Control animals were injected with buffer $(n=$ 10). Kaplan-Meier plot shows the survival of different treatment groups. Significant increase in animal survival is shown $(* p<0.05$, Log-Rank test). 
A

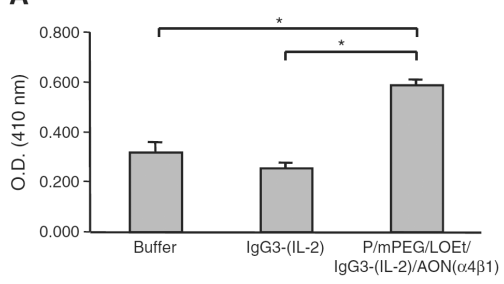

B

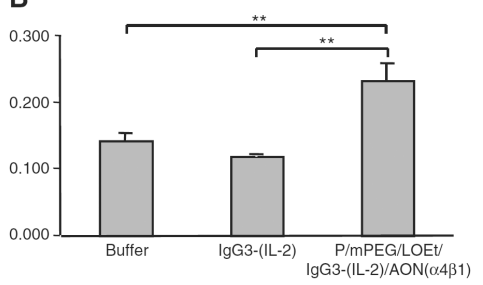

Fig. 6.

The induction of cellular and humoral immune responses in animals treated with the PMLAfusion nanobioconjugate. Blood samples were taken on day 27 after tumor inoculation from the tail vein from mice bearing D2F2/E2 tumors treated with buffer, the antibody-cytokine fusion protein, or the PMLA-fusion nanobioconjugate. Pooled samples were tested for mouse anti-HER2/neu $\operatorname{IgG1}(\mathrm{A})$ as a marker of the induction of a $\mathrm{T}_{\mathrm{H}} 2$ response and $\mathrm{IgG} 2 \mathrm{a}$ (B) as a marker for the induction of a $\mathrm{T}_{\mathrm{H}} 1$ response by ELISA. IgG1 level was determined using sera diluted 1:300 and IgG2a level was determined using sera diluted 1:100. Values represent the average of triplicate determinations of pooled serum aliquots and error bars indicate the standard deviation. Significant differences were determined using the Student's $t$-test $(* *)$ of $p<0.01$ and $(*) p<0.05$. 